\title{
National Identity and Social Welfare
}

\author{
Chee Meng Tan¹, Yoong Hon Lee, Pek Kim Ng² \\ ${ }^{1}$ Nottingham University Business School, University of Nottingham Malaysian Campus, Semenyih, Malaysia \\ ${ }^{2}$ School of Education, University of Nottingham Malaysian Campus, Semenyih, Malaysia \\ Email: cheemeng.tan@nottingham.edu.my
}

How to cite this paper: Tan, C.M., Lee, Y.H. and Ng, P.K. (2018) National Identity and Social Welfare. Theoretical Economics Letters, 8, 1665-1673. https://doi.org/10.4236/tel.2018.810107

Received: March 22, 2018

Accepted: June 16, 2018

Published: June 19, 2018

Copyright (C) 2018 by authors and Scientific Research Publishing Inc. This work is licensed under the Creative Commons Attribution International License (CC BY 4.0).

http://creativecommons.org/licenses/by/4.0/

\begin{abstract}
This paper investigates the relationship between national identification and social welfare. Society is a direct democracy where representative rich and poor agents vote on their most preferred tax rate. Utilizing the economics of identity, agent utility not only depends on income but also on social identification. We show that national identification increases agent utility and social welfare when the rich implements the most preferred tax rate of the poor, who is also the median voter. Furthermore, using respondent level of happiness as a proxy for social welfare, we show that national pride has a positive impact on welfare through logit regression analysis.
\end{abstract}

\section{Keywords}

National Identity, Social Welfare, Taxation, Democracy

\section{Introduction}

Nationalism has acquired a bad rap in recent times. Some consider it a main source of xenophobia, while others see it as a tool used by majority cultures to forcibly assimilate minority ones in the name of nation-building [1]. To make matters worse, nationalism is also the cornerstone of extreme idealogies such as Nazism and Fascism, both of which played an unrefutable role in initiating WW2.

Nonetheless, nationalism has its redeeming qualities. As an instance, national identity has aided states in overcoming colonialism and helped modernize the state [2]. Furthermore, recent works in social psychology have shown that national pride and national identification positively impact subjective well-being of individuals such as happiness and life satisfaction [3] [4].

This paper shows theoretically that national pride raises social welfare, which contributes to the literature where nationalism benefits society. We do so by uti- 
lizing the economics of identity where agents not only derive utility from material payoff, but from social identification as well. We support our results empirically through logit regression analysis, and show that national pride is positively correlated with happiness, which we proxy for welfare.

This paper is organized in the following manner. First, we discuss the theoretical model, which is an application of the economics of identity of Akerlof and Kranton [5] on the theory of political transitions by Acemoglu and Robinson (2006), to demonstrate that increasing national identity increases social welfare. Second, we will discuss the empirical analysis, which uses logit regression analysis to support the theoretical result. Finally, we conclude the paper with a short discussion.

\section{Model}

The nation is a direct democracy with rich $(r)$ and poor agents $(p)$ where agents vote for their most preferred tax rate. Members in each social class are identical and the proportion of rich and poor agents are $\delta$ and $1-\delta$, while the income of each rich and poor agent is $y_{r}$ and $y_{p}$. We assume the rich is the minority $(\delta<1 / 2)$ and the rich's income exceeds the poor's $\left(y_{r}>y_{p}\right)$. Let the nation's average income be $\bar{y}$, then $y_{p}<\bar{y}<y_{r}$. If society implements flat tax $\tau$, the posttax income of agent $i \in\{p, r\}$ is

$$
\pi_{i}(\tau)=(1-\tau) y_{i}+\left(\tau-\frac{\tau^{2}}{2}\right) \bar{y}
$$

where $\left(\tau^{2} / 2\right) \bar{y}$ is the quadratic deadweight lost following Bolton and Roland [6]. Note the average post-taxation income of the nation is

$$
\bar{\pi}(\tau)=\left(1-\frac{\tau^{2}}{2}\right) \bar{y}
$$

To model national identity, we apply the economics of identity [5]. According to identity economics, individuals not only derive utility from economic payoff, but also from social identification. This concept is grounded on social psychology, which theorizes that individuals derive emotional and value significance from social group membership [7]. Similar to Shayo [8] and Sambanis and Shayo [9], the utility of agent $i \in\{p, r\}$ is defined as

$$
U_{i}(\tau)=\pi_{i}+\sigma[s+\bar{\pi}(\tau)]-w d
$$

where $\sigma \in[0,1]$ is agent "pride" from national attributes that provide positive utility, such as $s>0$, which is exogenous and summarizes non-material dimensions impacting the nation and $\bar{\pi}(\tau)$ representing national economic strength. The coefficient $w \in[0,1]$ is the level of "shame" agents suffer from perceived negative national attributes $d>0$, which is determined exogenously. We restrict $\sigma+w=1$, hence a rise in national pride $\sigma$ causes shame $w$ to fall.

Substituting (1) and (2) into (3) and noting that $w=1-\sigma$, the utility of a poor agent is 


$$
U_{p}(\tau)=(1-\tau) y_{p}+\left(\tau-\frac{\tau^{2}}{2}\right) \bar{y}+\sigma\left[s+\left(1-\frac{\tau^{2}}{2}\right) \bar{y}\right]-(1-\sigma) d
$$

The poor's most preferred tax rate is defined as the tax rate that maximizes the poor's post-tax utility in (4). Since $\bar{y}>y_{p}$, the first order condition of the poor's utility with respect to $\tau$ is

$$
\tau_{p}=\frac{\bar{y}-y_{p}}{(1+\sigma) \bar{y}}>0
$$

which is decreasing in $\sigma$ since

$$
\frac{\mathrm{d} \tau_{p}}{\mathrm{~d} \sigma}=-\frac{\bar{y}-y_{p}}{(1+\sigma)^{2} \bar{y}}<0
$$

Note that this outcome is identical to that in Shayo [8]. For the rich, the utility is

$$
U_{r}(\tau)=(1-\tau) y_{r}+\left(\tau-\frac{\tau^{2}}{2}\right) \bar{y}+\sigma\left[s+\left(1-\frac{\tau^{2}}{2}\right) \bar{y}\right]-(1-\sigma) d
$$

and since $y_{r}>\bar{y}$, the first order condition of this utility with respect to $\tau$ is

$$
\frac{\mathrm{d} U_{r}(\tau)}{\mathrm{d} \tau}=-\left(y_{r}-\bar{y}\right)-(1+\sigma) \tau \bar{y}<0
$$

Hence, the most preferred tax rate of the rich is $\tau_{r}=0$ and we state the equilibrium below, which says that society implements $\tau_{p}$.

Proposition 1 A direct democracy with identical poor and identical rich agents with most preferred tax rates $\tau_{p}$ and $\tau_{r}$ will implement $\tau_{p}$ if the poor is the majority.

Proof: Since the poor is the majority and all poor agents are identical, the median voter is a poor agent. As only two policy choices $\tau_{p}$ and $\tau_{r}$ exist, the median voter theorem stipulates that society implements the most preferred tax rate of the poor.

We now define a social welfare function in the following to investigate the impact national identification on social welfare.

$$
W(\tau)=\delta U_{r}(\tau)+(1-\delta) U_{p}(\tau)
$$

The following proposition demonstrates the main result of this paper, which shows that when $\tau=\tau_{p}$, welfare in a direct democracy is increasing in national identification.

Proposition $2 W\left(\tau_{p}\right)$ increases in national pride $\sigma$.

Proof: By the chain rule

$$
\frac{\mathrm{d} U_{i}\left(\tau_{p}\right)}{\mathrm{d} \sigma}=\frac{\partial U_{i}\left(\tau_{p}\right)}{\partial \tau} \frac{\mathrm{d} \tau_{p}}{\mathrm{~d} \sigma}+\frac{\partial U_{i}\left(\tau_{p}\right)}{\partial \sigma}
$$

Since the first order condition of (4) implies that $\partial U_{p}\left(\tau_{p}\right) / \partial \tau=0$ and because $\partial U_{p}\left(\tau_{p}\right) / \partial \sigma=s+\left(1-\tau_{p}^{2} / 2\right) \bar{y}+d$,

$$
\frac{\mathrm{d} U_{p}\left(\tau_{p}\right)}{\mathrm{d} \sigma}=s+\left(1-\frac{\tau_{p}^{2}}{2}\right) \bar{y}+d>0
$$


For the rich

$$
\frac{\mathrm{d} U_{r}\left(\tau_{p}\right)}{\mathrm{d} \sigma}>0
$$

as

$$
\begin{aligned}
& \mathrm{d} \tau_{p} / \mathrm{d} \sigma<0 \text { in (6), } \partial U_{r} / \partial \tau<0 \text { in (8) } \\
& \text { and } \partial U_{r}\left(\tau_{p}\right) / \partial \sigma=s+\left(1-\tau_{p}^{2} / 2\right) \bar{y}+d>0 .
\end{aligned}
$$

Hence

$$
\frac{\mathrm{d} W\left(\tau_{p}\right)}{\mathrm{d} \sigma}=(1-\delta) \frac{\mathrm{d} U_{p}\left(\tau_{p}\right)}{\mathrm{d} \sigma}+\delta \frac{\mathrm{d} U_{r}\left(\tau_{p}\right)}{\mathrm{d} \sigma}>0
$$

\section{Empirical Analysis}

We demonstrate empirically that national pride positively impacts welfare. Works such as Frey and Stutzer [10] and Frey [11] indicate that subjective well-being (e.g. level of happiness or life satisfaction) is a satisfactory approximation of utility. As scholars often measure welfare using utility, we therefore proxy welfare using respondent happiness. We use integrated data from the European Value Survey (EVS) for 1981, 1990, 1999 and 2008, which is a comprehensive dataset that contains information on interviews conducted with respondents from 48 countries (mainly European), on opinions, beliefs, ideas, stated preferences, attitudes, and values related to family and work issues as well notions about religion, politics, as well as society ${ }^{1}$. We estimate the following using logit regression analysis':

$$
\begin{aligned}
\text { Happiness }_{i c t}= & \beta_{h 0}+\beta_{h 1} \text { National Pride }_{i c t}+\beta_{2 h} \text { Personal Characteristics }_{i c t} \\
& +\beta_{3} \text { Macro Controls }_{i c t}+\text { Country }_{c}+\text { Year }_{t}+\varepsilon_{i c t}
\end{aligned}
$$

The dependent variable Happiness ${ }_{i c t}$ is a dummy variable that measures the level of happiness of individual $i$ who resides in country $c$ in period $t$. For this variable, we use the EVS question "taking all things together how happy are you?" Responses are from a scale of 1 to 4 ("very happy", "quite happy", "not very happy", "not at all happy"). We create a happiness dummy such that "quite happy" and "very happy" are coded 1, and other responses are coded 0 . The

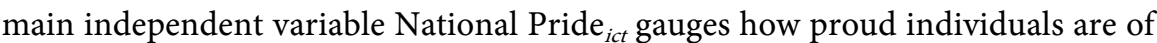
their nation. For this variable, we use the EVS question "How proud are you to be [e.g., French]?" where individuals answer on a scale of 1 to 4 ("very proud," "quite proud," "not very proud," and "not at all proud").

The vector Personal Characteristics ${ }_{i c t}$ includes respondents' income level (low, medium, high), age, gender, employment status ("full time", "Part time", "self-employed", "retired", "housewife", "student", "Unemployed", "Other"), marital status ("single", "married", "divorced", "separated", "widowed”). We also include the age when respondents completed formal schooling ("below fifteen", "fifteen to seventeen", “above seventeen"), respondent's number of child-

${ }^{1}$ For list of countries refer to Appendix.

${ }^{2}$ The analysis on national pride and happiness is similar to Ha and Jang [4], though we use logit instead of ordered probit. 
ren ("no child", "one child", "two children", "three and more"), and a dummy on whether respondents is religious ("a religious person", "not a religious per-

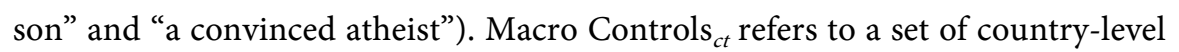
variables, which are real GDP per capita from the Expanded Trade and GDP database by Kristian Gleditsch, gini index from The Standardized World Income Inequality Database (SWIID), as well as unemployment and inflation rates using data from the World Bank.

Country dummies are present to account for country-specific traits and year dummies are present to capture any common shocks among countries. The error term is $\varepsilon_{i c t}$, which captures all omitted factors with $E\left(u_{i c t}\right)=0$ for all $i, c$ and $t$. All standard errors are fully robust to arbitrary heteroskedasticity and are clustered by country to account for serial correlation at the country level. The summary statistics not shown here is in the online Appendix.

Table 1 demonstrates that national pride is positively correlated with levels of happiness reported by respondents in democracies with scores of 9 or 10 in the Polity index, which represent highly democratic nations. Each column contains personal characteristics and macroeconomic controls described above, as well as country and year dummies.

Column 1 restricts the analysis to low income members of society and demonstrates that compared to individuals who are "not at all proud of the nation" (base case), respondents that are "not very proud of the nation" are $22.3 \%$ more likely to be happy, while individuals who are "quite proud of the nation" and "very proud of the nation" are $121 \%$ and $185 \%$ more likely to be happy. When the analysis includes both low and medium income groups in Column 2, and just the high income group in Column 3, results are similar to that in Column 1.

Table 1. Impact of national pride on happiness.

\begin{tabular}{ccccc}
\hline \multirow{2}{*}{$\begin{array}{c}\text { Dependent Variable: } \\
\text { Level of Happiness }\end{array}$} & $\begin{array}{c}\text { Low Income } \\
\text { Group }\end{array}$ & $\begin{array}{c}\text { Low \& Medium } \\
\text { All Income Group }\end{array}$ & $\begin{array}{c}\text { High Income } \\
\text { Group }\end{array}$ & $\begin{array}{c}\text { All Income } \\
\text { Group }\end{array}$ \\
\cline { 2 - 5 } & $(1)$ & $(2)$ & $(3)$ & $(4)$ \\
\hline Not very proud of nation & $1.214^{+}$ & $1.203^{* *}$ & $1.390^{+}$ & $1.249^{*}$ \\
& $(0.139)$ & $(0.099)$ & $(0.267)$ & $(2.221)$ \\
Quite proud of nation & $2.188^{* * *}$ & $2.155^{* * *}$ & $2.452^{* * *}$ & $2.221^{* * *}$ \\
& $(0.214)$ & $(0.167)$ & $(0.433)$ & $(0.201)$ \\
Very proud of nation & $2.822^{* * *}$ & $2.736^{* * *}$ & $2.776^{* * *}$ & $2.760^{* * *}$ \\
Countries & $(0.299)$ & $(0.237)$ & $(0.495)$ & $(0.258)$ \\
Observations & 33 & 33 & 33 & 33 \\
Personal characteristics & 22592 & 48790 & 21248 & 70038 \\
Yacroeconomic controls & Yes & Yes & Yes & Yes \\
Pseudo $R^{2}$ & 0.14 & Yes & Yes & Yes \\
\hline
\end{tabular}

${ }^{+} p<0.1 ;{ }^{*} p<0.05 ;{ }^{* *} p<0.01 ;{ }^{* *} p<0.001$. 
For all three income groups in Column 4, individuals that are "not very proud of nation" are $25 \%$ more likely to report happiness, while respondents that fall under the categories of "quite proud of nation" and "very proud of nation" are $123 \%$ and $177 \%$ more likely to express happiness in their lives. Hence increasing national pride implies a higher likelihood of happiness or welfare.

Robustness checks of the results for the low as well as low and medium income groups are illustrated in Table 2. Column 1 regresses happiness on national pride without personal characteristics and macroeconomic variables. Result shows that the impact of pride on happiness is positive across all categories of national pride, and the pride variables are at least significant at the level of $5 \%$. The same outcome applies for respondents from the low and medium income groups in columns 3 and 4, where increasing levels of national pride augments agent happiness with or without personal characteristics.

Table 3 presents robustness checks for respondents in the high income group and for all income levels. When not controlling for personal characteristics and macroeconomic variables, the variable corresponding to "not very proud of nation" is not statistically significant, though respondents who answer that they are "quite proud of the nation" or "very proud of the nation" are more likely than those in the base case (individuals who are "not at all proud of the nation") to state that they are happy. When controlling for personal characteristics without macro controls, we arrive at the same outcome.

When considering all income groups in columns 3 and 4 of Table 3 , all categories of national pride presented are positive and at least statistically significant at the level of $5 \%$. Nonetheless, respondents who say that they are "quite proud

Table 2. Robustness check: National pride on happiness.

\begin{tabular}{|c|c|c|c|c|}
\hline \multirow{2}{*}{$\begin{array}{l}\text { Dependent Variable: } \\
\text { Level of Happiness }\end{array}$} & \multicolumn{2}{|c|}{ Low Income Group } & \multicolumn{2}{|c|}{$\begin{array}{l}\text { Low \& Medium } \\
\text { All Income Group }\end{array}$} \\
\hline & (1) & (2) & (3) & $(4)$ \\
\hline \multirow{2}{*}{$\begin{array}{c}\text { Not very proud of } \\
\text { nation }\end{array}$} & $1.205^{\star}$ & $1.201^{\star}$ & $1.180^{*}$ & $1.158^{*}$ \\
\hline & $(0.114)$ & $(0.108)$ & $(0.091)$ & $(0.077)$ \\
\hline \multirow{2}{*}{ Quite proud of nation } & $1.961^{* * *}$ & $1.978^{* * *}$ & $1.963^{\star * *}$ & $1.926^{* * *}$ \\
\hline & $(0.170)$ & $(0.165)$ & $(0.153)$ & $(0.130)$ \\
\hline \multirow{2}{*}{ Very proud of nation } & $2.360^{* * *}$ & $2.585^{\star * *}$ & $2.284^{* * *}$ & $2.478^{\star * *}$ \\
\hline & $(0.204)$ & $(0.215)$ & $(0.175)$ & $(0.181)$ \\
\hline Countries & 36 & 36 & 36 & 36 \\
\hline Observations & 30518 & 28594 & 65988 & 61641 \\
\hline Personal characteristics & No & Yes & No & Yes \\
\hline $\begin{array}{l}\text { Macroeconomic } \\
\text { controls }\end{array}$ & No & No & No & No \\
\hline Pseudo $R^{2}$ & 0.10 & 0.15 & 0.10 & 0.16 \\
\hline
\end{tabular}


Table 3. Robustness check: National pride on happiness.

\begin{tabular}{|c|c|c|c|c|}
\hline \multirow{2}{*}{$\begin{array}{l}\text { Dependent Variable: } \\
\text { Level of Happiness }\end{array}$} & \multicolumn{2}{|c|}{ High Income Group } & \multicolumn{2}{|c|}{ All Income Group } \\
\hline & (1) & $(2)$ & (3) & (4) \\
\hline \multirow{2}{*}{$\begin{array}{l}\text { Not very proud of } \\
\text { nation }\end{array}$} & 1.221 & 1.196 & $1.225^{\star *}$ & $1.167^{*}$ \\
\hline & $(0.165)$ & $(0.171)$ & $(0.0872)$ & $(0.083)$ \\
\hline \multirow{2}{*}{ Quite proud of nation } & $1.995^{\star * *}$ & $1.991^{\star * *}$ & $1.963^{* * *}$ & $1.934^{\star \star \star}$ \\
\hline & $(0.274)$ & $(0.284)$ & $(0.155)$ & $(0.149)$ \\
\hline \multirow{2}{*}{ Very proud of nation } & $2.231^{\star * *}$ & $2.308^{\star * *}$ & $2.210^{* * *}$ & $2.442^{\star \star *}$ \\
\hline & $(0.278)$ & $(0.301)$ & $(0.166)$ & $(0.183)$ \\
\hline Countries & 36 & 36 & 36 & 36 \\
\hline Observations & 28109 & 26249 & 114325 & 87890 \\
\hline Personal characteristics & No & Yes & No & Yes \\
\hline $\begin{array}{l}\text { Macroeconomic } \\
\text { controls }\end{array}$ & No & No & No & No \\
\hline Pseudo $R^{2}$ & 0.10 & 0.13 & 0.09 & 0.16 \\
\hline
\end{tabular}

${ }^{+} p<0.1 ;{ }^{*} p<0.05 ;{ }^{* *} p<0.01 ;{ }^{* * *} p<0.001$.

of the nation" are at least $90 \%$ more likely to state that they are happy compared to individuals in the base case, while respondents who are "very proud of the nation" are at least $124 \%$ more likely than individuals in the base case to be happy.

\section{Conclusions}

We show theoretically that social welfare in direct democracies is increasing in national identity through the economics of identity. We substantiate this result by applying logit regression analysis on integrated data from the European Value Survey by demonstrating that happiness (proxy for social welfare) is positively correlated with national pride (proxy for national identity).

A number of studies using statistical methods have demonstrated that national pride is positively correlated with measures for subjective well-being such as happiness and satisfaction of life. However, to the best of our knowledge, none have tried to formulate a theoretical paper examining the connection between national pride and welfare/happiness. There are, however, potential limitations to this work. First, measuring social welfare through agent utility maybe a common approach taken by some, but it remains uncertain whether this approach is without fault since welfare is subjective. Second, even though some studies consider happiness a suitable representation for utility, some works dispute this assertion. Hence, proxying welfare with happiness is not without controversy.

\section{Acknowledgements}

Sincere thanks go to colleagues in the Nottingham University Business School at Malaysia for their support on this project and the anonymous reviewer for valuable feedback. 


\section{References}

[1] Mitchell, M. and Russell, D. (1996) Immigration, Citizenship and the Nation-State in the New Europe in Nation and Identity in Contemporary Europe. Routledge Press, London.

[2] Gellner, E. (2008) Nations and Nationalism. Blackwell, Oxford.

[3] Morrison, M., Tay, L. and Diener, E. (2011) Subjective Well-Being and National Satisfaction: Findings from a Worldwide Survey. Psychological Science, 121, 471-482. https://doi.org/10.1177/0956797610396224

[4] Ha, S. and Jang, S. (2015) National Identity, National Pride, and Happiness: The Case of South Korea. Social Indicators Research, 121, 471-482.

https://link.springer.com/article/10.1007/s11205-014-0641-7 https://doi.org/10.1007/s11205-014-0641-7

[5] Akerlof, G. and Kranton, R. (1982) Identity and the Economics of Organization. Journal of Economic Perspectives, 19, 9-32. https://www.aeaweb.org/articles?id=10.1257/0895330053147930 https://doi.org/10.1257/0895330053147930

[6] Bolton, P. and Gerard, R. (2005) The Breakup of Nations: A Political Economy Analysis. Quarterly Journal of Economics, 112, 1057-1090.

https://academic.oup.com/qje/article-abstract/112/4/1057/1911711?redirectedFrom $=$ fulltext https://doi.org/10.1162/003355300555420

[7] Tajfel, H. (1982) Social Identity and Intergroup Relations. Cambridge University Press, Cambridge.

[8] Shayo, M. (2009) A Model of Social Identity with an Application to Political Economy: Nation, Class, and Redistribution. The American Political Science Review, 103, 147-174. https://doi.org/10.1017/S0003055409090194

[9] Sambanis, N. and Shayo, M. (2013) Social Identification and Ethnic Conflict. The American Political Science Review, 107, 294-325.

https://doi.org/10.1017/S0003055413000038

[10] Frey, B., Stutzer, A. and Gerard, R. (2005) What Can Economists Learn from Happiness Research? Journal of Economic Literature, 40, 402-435.

https://www.aeaweb.org/articles?id=10.1257/002205102320161320 https://doi.org/10.1257/jel.40.2.402

[11] Frey, B. (2008) Happiness: A Revolution in Economics. MIT Press, Cambridge. https://doi.org/10.7551/mitpress/9780262062770.001.0001 


\section{Appendix}

\begin{tabular}{|c|c|}
\hline \multicolumn{2}{|c|}{ Country List used in EVS from 1981 to 2014} \\
\hline Albania & Kosovo \\
\hline Armenia & Latvia \\
\hline Austria & Lithuania \\
\hline Belarus & Luxembourg \\
\hline Belgium & Macedonia \\
\hline Bosnia-Herzegovina & Malta \\
\hline Bulgaria & Moldova \\
\hline Croatia & Montenegro \\
\hline Cyprus & Netherlands \\
\hline Northern Cyprus & Norway \\
\hline Czech Republic & Poland \\
\hline Denmark & Portugal \\
\hline Estonia & Romania \\
\hline Finland & Russia \\
\hline France & Serbia \\
\hline Georgia & Slovak Republic \\
\hline Germany & Slovenia \\
\hline Great Britain & Spain \\
\hline Greece & Sweden \\
\hline Hungary & Switzerland \\
\hline Iceland & Turkey \\
\hline Ireland & Canada \\
\hline Northern & Ukraine \\
\hline Italy & USA \\
\hline
\end{tabular}

